\title{
Expression of the cytoskeleton regulatory protein Mena in human gastric carcinoma and its prognostic significance
}

\author{
LIHUA XU ${ }^{1,2^{*}}$, HUO TAN $^{1 *}$, RUIMING LIU $^{3}$, QUNGAI HUANG $^{4}$, NANA ZHANG $^{5}$, XI LI $^{4}$ and JIANI WANG $^{4}$ \\ ${ }^{1}$ Department of Hematology and ${ }^{2}$ Guangdong Key Laboratory of Urology, The First Affiliated Hospital of \\ Guangzhou Medical University, Guangzhou, Guangdong 510230; ${ }^{3}$ First Affiliated Hospital of Sun Yat-sen \\ University, Laboratory of Department of Surgery, Guangzhou, Guangdong 510030; ${ }^{4}$ Breast Cancer Center, The \\ Third Affiliated Hospital of Sun Yat-sen University, Guangzhou, Guangdong 510000; ${ }^{5}$ Department of Pathology, \\ The Third Affiliated Hospital of Sun Yat-sen University, Guangzhou, Guangdong 510630, P.R. China
}

Received May 13, 2016; Accepted August 1, 2017

DOI: $10.3892 / \mathrm{ol} .2017 .6974$

\begin{abstract}
The cytoskeleton regulatory protein Mena is reportedly overexpressed in breast cancer; however, data regarding its expression level and clinical significance in gastric carcinoma (GC) is limited. The aim of the present study was to investigate Mena expression levels and prognostic significance in GC. Mena mRNA expression level was determined by reverse transcription-quantitative polymerase chain reaction in 10 paired $\mathrm{GC}$ and adjacent normal tissues. The Mena protein expression level was analyzed in paraffin-embedded GC samples and adjacent normal tissues by immunohistochemistry. Statistical analyses were also performed to evaluate the clinicopathological significance of Mena. The results revealed that the mRNA expression level of Mena was significantly higher in G Ct issues compared with in adjacent normal tissues from10 paired samples. In the paraffin-embedded tissue samples, the protein expression level of Mena was higher in G Ct issues compared with in adjacent normal tissues. Compared with adjacent normal tissues, Mena overexpression was observed in $52.83 \%$ (56/106) of patients. The overexpression of Mena was significantly associated with the $\mathrm{T}$ stage $(\mathrm{P}=0.033)$, tumor-node-metastasis (TNM) stage $(\mathrm{P}<0.001)$ and decreased overall survival $(\mathrm{P}<0.001)$. Based on a multivariate analysis, Mena expression level was an independent prognostic factor for overall survival time. In conclusion, Mena wasoverexpressed in $\mathrm{G} \mathrm{C}$ tissues and significantly associated with the T stage, TNM stage and overall survival time. Mena may therefore be suitable as a prognostic indicator for patients with GC.
\end{abstract}

Correspondence to: Dr Jiani Wang or Dr Xi Li, Breast Cancer Center, The Third Affiliated Hospital of Sun Yat-sen University, 600 Tianhe Road, Guangzhou, Guangdong 510000, P.R. China

E-mail: turtle_w@163.com

E-mail: dr-lixi@21cn.com

*Contributed equally

Key words: gastric carcinoma, Mena, overexpression, prognosis

\section{Introduction}

The morbidity associated with gastric carcinoma (GC) has declined in recent decades; however, GC remains the fourth most common carcinoma and second highest cause of cancer-associated mortality worldwide (1). In 2012, there werean estimated 951,600 new cases and 723,100 GC-associated mortalities (1). Despite progression in diagnosis and treatment methods, the prognosis for patients with GC remains poor. Due toinconspicuous symptoms in the early stages, the vast majority of patients with GC are already in the advanced stages at the time of first diagnosis, resulting in a poor prognosis $(2,3)$. Therefore, the early diagnosis and treatment of GC are of critical importance for improving the clinical outcome.

Mena (also referred to as ENAH-enabled homolog) is a member of the Ena/vasodilator-stimulated phosphoprotein (VASP) family of actin-binding proteins, which function in diverse types of cell $(4,5)$. Ena/VASP proteins are key regulatory molecules that control the cell shape, movement and actin organization on cadherin adhesion contacts, which are frequently affected following malignant transformation $(4,6)$. Mena is a key mediator of cytoskeletal arrangement (7). It regulates cell movement by protecting actin filaments from capping proteins during polymerization (8). An upregulated Mena expression level was previously reported in mouse and rat invasive breast carcinoma (9), as well as in human breast cancer cell lines and tissues (10). Similarly, Mena expression was observed to beupregulated in human hepatocellular carcinoma (11), colorectal carcinoma (12), cervix precursor lesions (13) and pancreatic tumor cell lines as well as in primary and metastatic pancreatic tumors (14); in normal tissue, Mena expression level was reported at low or non-detectable levels (11). However, the clinical significance of Mena in GC remains indistinct. The present study investigated the expression level of Mena in GC to reveal its clinicopathological significance.

\section{Materials and methods}

Patients and tissue samples. The present study was performed with 106 GC paraffin-embedded tissue samples collected during resection from the Third Affiliated Hospital of Sun Yat-sen 
University (Guangzhou, China) between January 2001 and December 2004 for immunohistochemical (IHC) analysis. The median age of the patients was 54 years old (range, 29-72 years) and the median tumor size was $6.0 \mathrm{~cm}$ (range, 0.8 $-15.0 \mathrm{~cm}$ ); the group included 67 male and 39 female patients. From these 106 patients, 32 samples of adjacent non-cancerous tissues were additionally collected as control samples. All patients were pathologically diagnosed with gastric adenocarcinoma. None of the patients had received any type of neoadjuvant therapy and all underwent a radical excision. The clinical information for these samples is summarized in Table I. The date of patient surgery was defined as the initial event of survival analysis, and the date of patient mortality or the censoring of the patient at the last follow-up date was defined as the end time. The interval was defined as the overall survival time for patients.

In addition, 10 paired GC and adjacent normal tissues (the adjacent normal tissue was defined as at least $5 \mathrm{~cm}$ from the tumor edge) were collected from the Third Affiliated Hospital of Sun Yat-sen University between June 2013 and February 2015 for reverse transcription-quantitative polymerase chain reaction (RT-qPCR) analysis. The group included 7 male and 3 female patients, and the median age of the patients was 51 years old (range, 32-69 years). Tissues were collected immediately after surgery.

The clinicopathological classification and staging were determined according to the American Joint Committee on Cancer criteria (15). Written informed consent was obtained from all patients prior to enrollment in the present study. The present study was approved by the Institutional Research Ethics Committee of the Third Affiliated Hospital of Sun Yat-sen University.

RT-qPCR analysis. Total RNA samples were extracted from 10 paired GC and adjacent normal tissues using TRIzol ${ }^{\circledR}$ reagent (Invitrogen; Thermo Fisher Scientific, Inc., Waltham, MA, USA) according to the manufacturer's protocol. Extracted RNA was pretreated with RNase-free DNase. For cDNA synthesis, $2 \mu \mathrm{g}$ RNA from each sample was used, according to the RevertAid ${ }^{\mathrm{TM}}$ First Strand cDNA Synthesis kit instructions (K1622; Thermo Fisher Scientific, Inc.).

For the PCR amplification of Mena cDNA, SYBR-Green 2X master mixture (170-8882AP; Bio-Rad Laboratories, Inc., Hercules, CA, USA) was used in a total volume of $20 \mu 1$, according to the manufacturer's instructions, an initial amplification step using Mena-specific primers was performed with a denaturation at $95^{\circ} \mathrm{C}$ for $10 \mathrm{~min}$, which was followed by 28 denaturation cycles at $95^{\circ} \mathrm{C}$ for $60 \mathrm{sec}$, primer annealing at $58^{\circ} \mathrm{C}$ for $30 \mathrm{sec}$ and primer extension at $72^{\circ} \mathrm{C}$ for $30 \mathrm{sec}$. Upon completion of the cycling steps, a final extension at $72^{\circ} \mathrm{C}$ for $5 \mathrm{~min}$ was performed prior to the storage of the reaction mixture at $4^{\circ} \mathrm{C}$. The primer sequences were as follows: Mena sense, 5'-GTGCCATTCCTAAAGGGTTGA-3' and antisense, 5'-GCTGCCAAAGTTGAGACCATAC-3'; GAPDH sense, 5'-TGTTGCCATCAATGACCCC-3' and antisense, 5'-CTC CACGACGTACTCAGC-3'. The primers were designed with Primer Express version 2.0 software (Applied Biosystems; Thermo Fisher Scientific, Inc.).

GAPDH was used as an internal control, the relative expression level of Mena was calculated using the $2^{-\Delta \Delta \mathrm{CT}}$ method (16); all experiments were performed in triplicate.
IHC analysis. IHC staining was performed to investigate the alteration to protein expression levels in 106 human GC tissues and 32 paired adjacent non-cancerous tissues. Briefly, 4- $\mu$ m-thick paraffin sections of the tissue were deparaffinized with xylene and rehydrated in a descending alcohol series. Antigenic retrieval was performed by submerging the slides in EDTA antigenic retrieval buffer and microwave heating for $3 \mathrm{~min}$ at $650 \mathrm{~W}$ and thentwice more at $350 \mathrm{~W}$ for $3 \mathrm{~min}$. To quench endogenous peroxidase activity, the slides were treated with $3 \%$ hydrogen peroxide in methanol and then incubated with $1 \%$ bovine serum albumin (Santa Cruz Biotechnology, Inc., Santa Cruz, CA, USA) at room temperature for $60 \mathrm{~min}$ to block nonspecific binding. Subsequently, tissue sections were incubated with a rabbit polyclonal anti-Mena antibody (dilution, 1:100; BD Biosciences, Franklin Lakes, NJ, USA, catalog number: 5111-1) at $4^{\circ} \mathrm{C}$ overnight. Normal goat serum (Santa Cruz Biotechnology, Inc.) was used at $4^{\circ} \mathrm{C}$ overnight as a negative control. The tissue sections were incubated with a biotinylated anti-rabbit secondary antibody (no dilution; Santa Cruz Biotechnology, Inc.; catalog number: sc-2040) at room temperature for 30 min following 3 washes in PBS, followed by further incubation with a streptavidin-horseradish peroxidase complex (dilution, 1:1500; Abcam, Cambridge, UK; catalog number: ab7403) at room temperature for $30 \mathrm{~min}$. Slides were immersed in 3-amino-9-ethyl carbazole room temperature for 3 min and then counterstained with 10\% Mayer's hematoxylin at room temperature for $30 \mathrm{sec}$. Finally, they were dehydrated and mounted with Crystal Mount.

Slides were imaged at magnification $\mathrm{x} 20\left(0.5 \mathrm{x} 0.5 \mu \mathrm{m}^{2}\right.$ pixel resolution) using a WSI instrument (ScanScope CS, Aperio, Vista, CA, USA) fitted with a 20x/0.75 Plan Apo objective lens (Olympus, Center Valley, PA, USA). For the evaluation of immunostaining, the degree of immunostaining was viewed and scored independently by two pathologists, who were blinded to the histopathological characteristics and patient information for the samples. The mean value of the scores provided by the two independent pathologists was used for the comparative evaluation of Mena expression.

The intensity of Mena staining was graded according to the following criteria: 0 , no staining; 1 , weak staining (light yellow); 2, moderate staining (yellow brown); and 3, strong staining (brown). The percentage of stained tumor cells was scored as follows: 0 , no positive tumor cells; $1,1-25 \%$ positive tumor cells; $2,26-50 \%$ positive tumor cells; $3,51-75 \%$ positive tumor cells; and $4,>75 \%$ positive tumor cells.

The staining score was evaluated as the product of the proportion of positive tumor cells and the staining intensity score. The expression level of Mena was defined as follows: '-' (score 0, negative), '+' (score 1-4, weakly positive), '++' (score 5-8, positive) and ' +++ ' (score 9-12, strongly positive). Optimal cut-off values for Mena expression were selected based on the analysis of overall survival (OS) data with the log-rank test. A staining index score of $\geq 4$ was used to define tumors with high Mena expression level whereas $<4$ indicated a low Mena expression level.

Statistical analysis. All statistical analyses were performed using SPSS 20.0 software (IBM Corp., Armonk, NY, USA). The difference in Mena expression levels between GC tissues and adjacent non-cancer tissues were analyzed using the 
Table I. Association between Mena expression level and clinicopathological characteristics.

\begin{tabular}{|c|c|c|c|c|}
\hline \multirow[b]{2}{*}{ Characteristics } & \multirow[b]{2}{*}{ Total } & \multicolumn{2}{|c|}{ Mena expression status } & \multirow[b]{2}{*}{ P-value } \\
\hline & & Negative (\%) & Positive (\%) & \\
\hline Total & 106 & 50 & 56 & \\
\hline Gender & & & & 0.573 \\
\hline Male & $67(63.2)$ & $33(49.3)$ & $34(50.7)$ & \\
\hline Female & $39(36.8)$ & $17(43.6)$ & $22(56.4)$ & \\
\hline Age (years) & & & & 0.065 \\
\hline$\geq 60$ & $46(43.4)$ & $17(37.0)$ & $29(63.0)$ & \\
\hline$<60$ & 60 (56.6) & $33(55.0)$ & $27(45.0)$ & \\
\hline T stage & & & & 0.033 \\
\hline 1 & $10(9.4)$ & $8(80)$ & $2(20)$ & \\
\hline 2 & $10(9.4)$ & $7(70)$ & $3(30)$ & \\
\hline 3 & $84(79.2)$ & $34(40.5)$ & $50(59.5)$ & \\
\hline $4 \mathrm{a}$ & $2(1.9)$ & $1(50)$ & $1(50)$ & \\
\hline $\mathrm{N}$ stage & & & & 0.313 \\
\hline 0 & $21(19.8)$ & $13(61.9)$ & $8(38.1)$ & \\
\hline 1 & $38(35.8)$ & $17(44.7)$ & $21(55.3)$ & \\
\hline 3 & $47(44.3)$ & $20(42.6)$ & $27(57.4)$ & \\
\hline M stage & & & & 0.813 \\
\hline 0 & $99(93.4)$ & $47(47.5)$ & $52(52.3)$ & \\
\hline 1 & $7(6.6)$ & $3(42.9)$ & $4(57.1)$ & \\
\hline TNM stage & & & & $<0.001$ \\
\hline I & $13(12.3)$ & $12(92.3)$ & $1(7.7)$ & \\
\hline II & $18(17.0)$ & $14(77.8)$ & $4(22.2)$ & \\
\hline III & $68(64.2)$ & $23(33.8)$ & $45(66.2)$ & \\
\hline IV & $7(6.6)$ & $1(14.3)$ & $6(85.7)$ & \\
\hline Tumor size $(\mathrm{cm})$ & & & & 0.419 \\
\hline$\geq 5$ & $74(69.8)$ & $33(44.6)$ & $41(55.4)$ & \\
\hline$<5$ & $32(30.2)$ & $17(53.1)$ & $15(46.9)$ & \\
\hline Grade & & & & 0.570 \\
\hline 1 & $4(3.8)$ & $3(75)$ & $1(25)$ & \\
\hline 2 & $25(23.6)$ & $11(44.0)$ & $14(56.0)$ & \\
\hline 3 & $76(71.7)$ & $36(47.4)$ & $40(52.6)$ & \\
\hline 4 & $1(9)$ & $0(0)$ & $1(100)$ & \\
\hline Infiltration & & & & 0.742 \\
\hline 0 & $101(95.3)$ & $48(47.5)$ & $53(52.5)$ & \\
\hline 1 & $5(4.7)$ & $2(40.0)$ & $3(60.0)$ & \\
\hline
\end{tabular}

T, tumor; $\mathrm{N}$, node; $\mathrm{M}$, metastasis.

$\chi^{2}$ test. Survival curves were plotted using the Kaplan-Meier method and compared using the log-rank test. The association between Mena expression level and other clinicopathological characteristics was analyzed usingthe $\chi^{2}$ and Fisher's exact tests. Bivariate correlations between the clinicopathological characteristics were determined using Spearman's rank correlation coefficients. Clinicopathological characteristics used to predict the prognosis in clinical practice were evaluated by univariate and multivariate Cox regression analyses. The selected type of Cox model for the univariate analysis was the 'enter' method, and for the multivariate analysis, the 'forward' method. $\mathrm{P}<0.05$ was considered to indicate a statistically significant difference.

\section{Results}

Mena is overexpressed in GC tissues. To determine whether Mena expression isupregulated in human GC, RT-qPCR was performed on 10 paired GC and adjacent normal tissues. As presented in Fig. 1, the expression level of Mena mRNA 
was higher in all $10 \mathrm{GC}$ tissue samples compared with in adjacent normal tissues, with the difference in expression level ranging from 1.5 to 84 -fold. In IHC results, the high expression of Mena was observed in $52.83 \%$ (56/106) of the patients with GC, whereas weak or no staining was observed in $47.17 \%$ of the tumor samples (Table I). In the adjacent non-tumor tissues, Mena protein staining was largely weak or absent; there was a $6.25 \%(2 / 32)$ positive expressionrate detected. The difference between these two groups was statistically significant $\left(\chi^{2}=18.910 ; \mathrm{P}<0.001\right)$. As presented in Fig. 2 , Mena staining occurred predominantly in the cytoplasm.

Mena overexpression is associated with GC clinical characteristics. To better understand the potential role of Mena in the development and progression of GC, the association of Mena expression level with other clinicopathological indexes in 106 paraffin-embedded archived GC tissues, including 10 stage I tumors, 10 stage II tumors, 84 stage III tumors and 2 stage IVa tumors, was investigated.

As summarized in Table I, there were no significant associations between Mena expression level and the gender, age, node (N) or metastasis (M) stage, tumor size, grade and the infiltration of adjacent organs in the patients; however, the expression level of Mena was significantly associated with the tumor ( $\mathrm{T} ; \mathrm{P}=0.033)$ and TNM stages $(\mathrm{P}<0.001)$.

Association between Mena expression level and overall patient survival time. Survival analysis revealed a clear negative association between the expression level of Mena protein and the OS time of patients with GC ( $\mathrm{P}<0.001$; Fig. 3A). In addition, Cox regression analysis revealed that Mena expression level, $\mathrm{T}$ stage and $\mathrm{N}$ stage were independent prognostic factors for OS time (Table II).

The prognostic significance of Mena expression status in selective subgroups stratified by the T stage and TNM stage was analyzed. For patients with late-stage tumors (stage III-IVa), the expression level of Mena was strongly associated with the OS duration (Fig. 3B; $\mathrm{P}=0.001$ ), which was not the case for patients with early-stage tumors (stages I-II; Fig. 3C; $\mathrm{P}=0.181$ ). Similarly, when it was evaluated according to $\mathrm{T}$ stage, the effect on outcome associated with the expression level of Mena was significant only in the T3-4 subgroup (Fig. 3D; $\mathrm{P}=0.004$ ), and not in the T1-2 subgroup (Fig. 3E, P=0.200).

\section{Discussion}

GC is the fourth most common type of cancer and the second leading cause for cancer-associated mortality worldwide, although it exhibits a decreasing trend of incidence $(1,17)$. There has been significant clinical progress in the early diagnosis and treatment of $\mathrm{GC}$ during recent decades; however, it is usually diagnosed at a late stage, resulting in a high treatment cost and decreasing the rate of successful curative surgery (18). The 5-year OS rate for GC is closely associated with the tumor stage. Patients diagnosed at stage I exhibit a 5-year OS rate of $>90 \%$, whereas patients diagnosed at stage IV exhibit a 5-year OS rate of $<5 \%$ (19). Therefore, there is currently a great clinical demand for early diagnosis and treatment, which are pivotal for improving the outcome of GC.

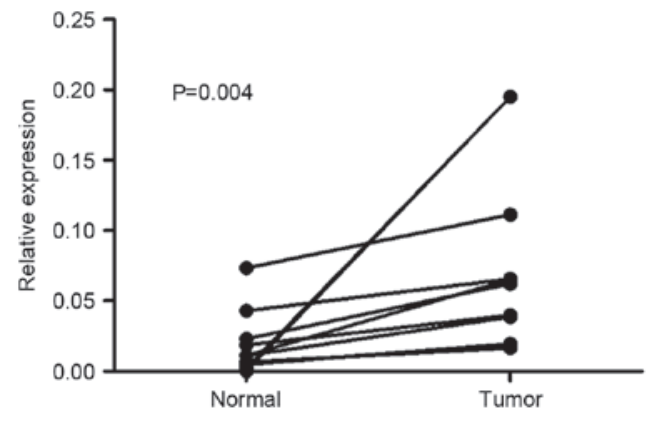

Figure 1. Expression level of Mena mRNA in GC and adjacent non-cancerous tissues. The expression levels of Mena mRNA relative to GAPDH in ten paired GC and adjacent non-cancerous tissues were evaluated by reverse transcription-quantitative polymerase chain reaction analysis. GC, gastric carcinoma.

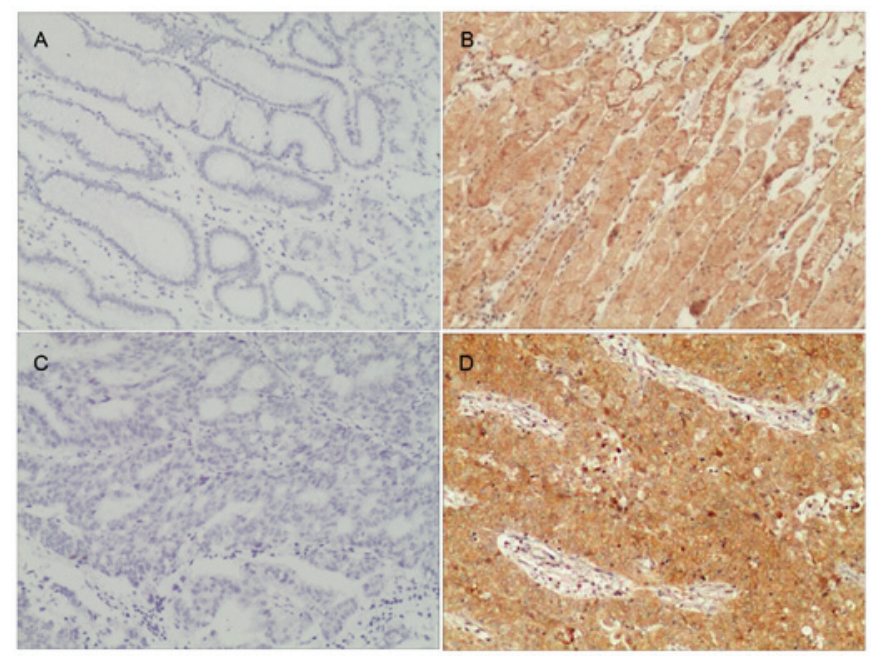

Figure 2. Analysis of Mena protein expression by immunohistochemistry. Mena expression was predominantly localized in the cytoplasm of gastric tumor cells. Representative images of (A) negative, (B) positivestaining for Mena in normal gastric tissues; representative images of (C) negative, (D) positivestaining of Mena in gastric carcinoma tissues. Magnification, $\mathrm{x} 200$.

Classical serum tumor markers, including carcinoembryonic antigen and carbohydrate antigen 19-9 have definite implications for GC diagnosis and monitoring, but the lack of specificity and sensitivity impaired their function (20). In recent years, there have been multiple novel tissue-based biomarkers for GC identified, including vascular endothelial growth factor receptor 2 (21), excision repair cross-complementation group 1 (22), human epidermal growth factor receptor-2 $(23,24), \mathrm{Bcl}-2$ and Ki-67 (25). However, most of these molecular markers are not conventionally used in the clinical setting as they do not accurately and efficiently predict the clinical outcome or curative effect. Novel tumor molecular markers are thus required to improve the detection, diagnosis and prognosis of GC.

Human ortholog of murine Mena, a member of the Ena/VASP protein family that includes Mena, VASP and Evl in mammals, is a key actin polymerization regulatory protein involved in the assembly and dynamics of cytoplasmic actin networks (26). The Ena/VASP family is an important regulator of actin cytoskeleton dynamics involved in cell motility. 
Table II. Cox-regression analysis of various prognostic parameters in patients.

\begin{tabular}{|c|c|c|c|c|}
\hline \multirow[b]{2}{*}{ Factor } & \multicolumn{2}{|c|}{ Univariate } & \multicolumn{2}{|c|}{ Multivariate } \\
\hline & $\operatorname{HR}(95 \% \mathrm{CI})$ & P-value & $\operatorname{HR}(95 \% \mathrm{CI})$ & P-value \\
\hline $\mathrm{N}$ stage & & $<0.001$ & & 0.002 \\
\hline 0 & Reference & & Reference & \\
\hline 1 & $4.022(1.955-8.274)$ & & $1.718(0.784-3.766)$ & \\
\hline 3 & $7.015(3.421-14.386)$ & & $3.273(1.533-6.988)$ & \\
\hline Age & & 0.001 & & \\
\hline$\geq 60$ & Reference & & & \\
\hline$<60$ & $0.481(0.319-0.727)$ & & & \\
\hline Tumor size $(\mathrm{cm})$ & & 0.001 & & \\
\hline$<5$ & Reference & & & \\
\hline$\geq 5$ & $0.439(0.272-0.709)$ & & & \\
\hline Mena expression status & & $<0.001$ & & 0.010 \\
\hline Negative & Reference & & & \\
\hline Positive & $0.433(0.284-0.661)$ & & $0.463(0.296-0.724)$ & \\
\hline T stage & & 0.001 & & 0.005 \\
\hline 1 & Reference & & Reference & \\
\hline 2 & 17.539 (2.207-139.398) & & $9.680(1.142-82.080)$ & \\
\hline 3 & $36.233(4.970-264.173)$ & & $16.096(1.974-133.049)$ & \\
\hline 4 & $16.855(1.516-188.064)$ & & $2.845(0.217-37.316)$ & \\
\hline
\end{tabular}

HR, hazard ratio; CI, confidence interval; N, node; T, tumor.
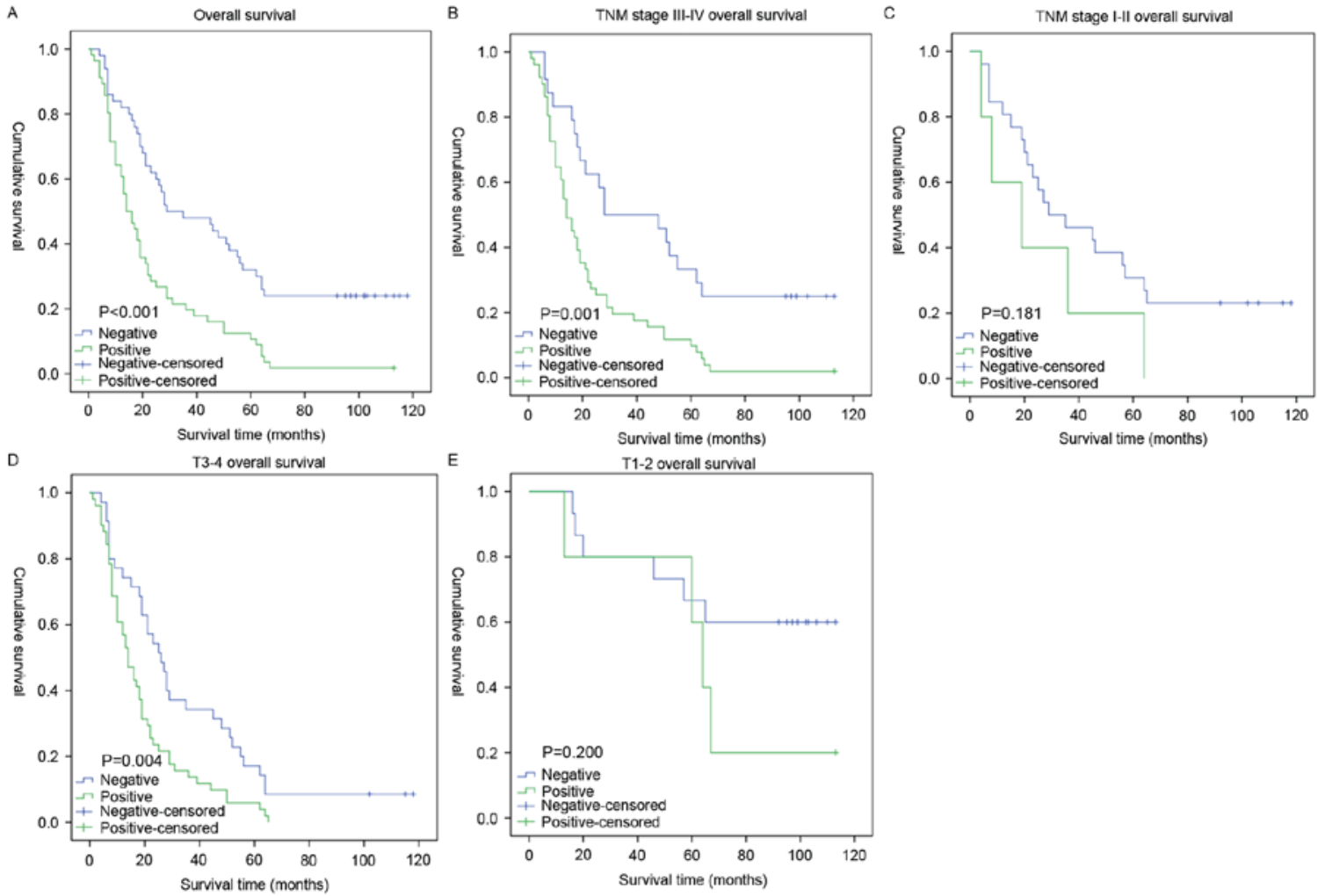

Figure 3. Kaplan-Meier OS curves for patients with gastric carcinoma tumors withhigh and low Mena expression. (A) OS curves for patients with high vs. low Mena expression levels. (B) OS curves for patients with late TNM stages (III-IVa) with high vs. low Mena expression levels. (C) OS curves for patients with early TNM stages (I-II) with high vs. low Mena expression levels. (D) OS curves for patients with T stage 3-4 gastric tumors with high vs. low Mena expression levels. (E) OS curves for patientswith T stage 1-2 gastric tumors with high vs. low Mena expression levels in patients. P-values were produced with a log-rank test. OS, overall survival; TNM, tumor-node-metastasis. 
Additionally, alterations to the cellular actin network serve an important role in malignant transformation and tumor progression. Members of the Ena/VASP family that are localized at the tips of protruding filopodia and lamellipodia and adhesion foci function in the control of cell movement, shape and adhesion, which are important biological processesin the development of metastatic potential (27). Located on chromosome 1, the Mena gene encodes the 570-residue Mena protein and alternative splicing-derived isoforms (28). As a member of the Ena/VASP family, Mena regulates membrane protrusion and cell movement in various types of cells and contexts by influencing the geometry and assembly of actin filament networks through the binding of G-actin and F-actin (26,29-32).

Mena enhances tumor cell migration toward epidermal growth factor (EGF) in part by interfering with the activity of the inhibitory capping proteins and increasing actin filament elongation, promoting actin polymerization $(26,33,34)$. The anti-capping activity of Mena is proposed to amplify the barbed end output of the cofilin and Arp2/3 complex pathways, particularly in response to EGF, which is important in the metastatic potential of mammary tumors $(26,29,35)$. Di Modugno et al (28) revealed that Mena is overexpressed in $75 \%$ of primary mammary carcinomas; consistent with this observation, high expression levels of Mena in breast cancer patients have been associated with poor prognosis $(28,36)$. Similarly, in precancerous lesions of the cervix and colon, the expression of Mena was upregulated with progressive transformation $(13,37)$. It was also detected in pancreatic carcinoma cell lines and in primary and metastatic pancreatic tumor tissues $(28,36,38)$. Mena maintains the stability of invadopodia, actin-rich protrusions that contain proteases, increasing the matrix degradation activity of tumor cells. Mena activity potentiates EGF-induced tumor cell invasion and membrane protrusion. These previous studies demonstrate that the overexpression of Mena in cancer enables the invasion and metastasis of tumor cells in response to otherwise benign EGF stimulus levels, increasingthe responsiveness to macrophage signaling (26).

The present study presented novel evidence that the upregulation of Mena was associated with poor clinical outcomes in patients with GC, particularly for those with late-stage disease. It was clearly demonstrated that in GC tissues, the expression of Mena at the mRNA and protein levels was markedly higher compared with in the adjacent normal tissues. Therefore, Mena may be a biomarker for GC, which may aid precise diagnoses. However, at present, the precise functions of Mena in human cancer remain unclear. The overexpression of Mena in GC may reflect the aberrant regulation of actin dynamics. However, understanding of the precise mechanism underlying Mena in GC requires further investigation.

The present study additional lyinvestigated the association between Mena expression level and other clinical features of patients with GC. There was a significant association between Mena expression level and the T and TNM stages, which revealed that Mena may be used as an independent biomarker for the recognition of a subpopulation of GC patients with more aggressive disease. However, the associations between Mena and the gender, age, $\mathrm{N}$ stage, $\mathrm{M}$ stage, tumor size, grade, and infiltration in patients with GC were not significant.
Previous studies have reported the prognostic value of Mena in human cancer. For example, numerous studies have observed that high expression levels of Mena areassociated with a poor prognosis in patients with breast cancer $(28,36)$. However, to the best of our knowledge, the prognostic value of Mena in GC has not previously been explored. In the present study, patients with high Mena expression levels had a $1.79 \%$ cumulative 10 -year survival rate, which was significantly lower than patients in the low Mena expression group $(24.0 \%)$. Multivariate analysis revealed that the expression level of Mena may be an independent prognostic factor for OS time in GC patients (Table II). Of note, a sub-group analysis demonstrated that patients with high Mena expressionand poor clinical out comes also demonstrated the features of late TNM and $\mathrm{T}$ stages.

In conclusion, to the best of our knowledge, this is the first study to investigate Mena expression level and its clinicopathological and prognostic significance in GC. The results of the present study suggested that Mena was upregulated in GC tissues and associated with the T and TNM stages. Multivariate analysis revealed that Mena may be an independent molecular marker for the prediction of GC prognosis and survival. Therefore, detecting the Mena protein expression level may aid the stratification of patients as a novel therapeutic strategy and establish a rational treatment selection criterion for patients with GC. Further, in-depth study will berequired to investigate the molecular mechanism underlying Mena involvement in the development and progression of GC.

\section{Acknowledgements}

The present study was supported by the National Natural Science Foundation of China (grant nos. 81672661 and 81502268) and grants from the Guangdong Province Natural Science Foundation (grant nos. 2015A030310126 and 2015A030313182).

\section{References}

1. Torre LA, Bray F, Siegel RL, Ferlay J, Lortet-Tieulent J and Jemal A: Global cancer statistics, 2012. CA Cancer J Clin 65: 87-108, 2015.

2. Kim BS, Cho SW, Min SK and Lee BH: Differences in prognostic factors between early and advanced gastric cancer. Hepatogastroenterology 58: 1032-1040, 2011.

3. Saragoni L: Upgrading the definition of early gastric cancer: Better staging means more appropriate treatment. Cancer Biol Med 12: 355-361, 2015.

4. Krause M, Dent EW, Bear JE, Loureiro JJ and Gertler FB: Ena/VASP proteins: Regulators of the actin cytoskeleton and cell migration. Annu Rev Cell Dev Biol 19: 541-564, 2003.

5. Tang D, Zhang X, Huang S, Yuan H, Li J and Wang Y: Mena-GRASP65 interaction couples actin polymerization to Golgi ribbon linking. Mol Biol Cell 27: 137-152, 2016.

6. Chen XJ, Squarr AJ, Stephan R, Chen B, Higgins TE, Barry DJ, Martin MC, Rosen MK, Bogdan S and Way M: Ena/VASP proteins cooperate with the WAVE complex to regulate the actin cytoskeleton. Dev Cell 30: 569-584, 2014.

7. Takahashi K and Suzuki K: WAVE2, N-WASP, and Mena facilitate cell invasion via phosphatidylinositol 3-kinase-dependent local accumulation of actin filaments. J Cell Biochem 112: 3421-3429, 2011.

8. Barzik M, Kotova TI, Higgs HN, Hazelwood L, Hanein D, Gertler FB and Schafer DA: Ena/VASP proteins enhance actin polymerization in the presence of barbed end capping proteins. J Biol Chem 280: 28653-28662, 2005. 
9. Wang W, Wyckoff JB, Goswami S, Wang Y, Sidani M, Segall JE and Condeelis JS: Coordinated regulation of pathways for enhanced cell motility and chemotaxis is conserved in rat and mouse mammary tumors. Cancer Res 67: 3505-3511, 2007.

10. Du JW, Xu KY, Fang LY and Qi XL: Clinical significance of Mena and Her-2 expression in breast cancer. Eur J Gynaecol Oncol 33: 455-458, 2012

11. Hu K, Wang J, Yao Z, Liu B, Lin Y, Liu L and Xu L: Expression of cytoskeleton regulatory protein Mena in human hepatocellular carcinoma and its prognostic significance. Med Oncol 31: 939, 2014

12. Toyoda A, Kawana H, Azuhata K, Yu J, Omata A, Kishi H, Higashi $\mathrm{M}$ and Harigaya $\mathrm{K}$ : Aberrant expression of human ortholog of mammalian enabled (hMena) in human colorectal carcinomas: Implications for its role in tumor progression. Int J Oncol 34: 53-60, 2009.

13. Gurzu S, Jung I, Prantner I, Chira L and Ember I: The immunohistochemical aspects of protein Mena in cervical lesions. Rom J Morphol Embryol 50: 213-216, 2009.

14. Pino MS, Balsamo M, Di Modugno F, Mottolese M, Alessio M, Melucci E, Milella M, McConkey DJ, Philippar U, Gertler FB, et al: Human Mena+11a isoform serves as a marker of epithelial phenotype and sensitivity to epidermal growth factor receptor inhibition in human pancreatic cancer cell lines. Clin Cancer Res 14: 4943-4950, 2008.

15. Rutkowski P, Wozniak A, Debiec-Rychter M, Kakol M, Dziewirski W, Zdzienicki M, Ptaszynski K, Jurkowska M, Limon J and Siedlecki JA: Clinical utility of the new American Joint Committee on Cancer staging system for gastrointestinal stromal tumors: Current overall survival after primary tumor resection. Cancer 117: 4916-4924, 2011.

16. Arocho A, Chen B, Ladanyi M and Pan Q: Validation of the 2-DeltaDeltaCt calculation as an alternate method of data analysis for quantitative PCR of BCR-ABL P210 transcripts. Diagn Mol Pathol 15: 56-61, 2006.

17. Hamashima $\mathrm{C}$ : Current issues and future perspectives of gastric cancer screening. World J Gastroenterol 20: 13767-13774, 2014.

18. Jemal A, Bray F, Center MM, Ferlay J, Ward E and Forman D Global cancer statistics. CA Cancer J Clin 61: 69-90, 2011.

19. Matsuda T, Ajiki W, Marugame T, Ioka A, Tsukuma H and Sobue T; Research Group of Population-Based Cancer Registries of Japan: Population-based survival of cancer patients diagnosed between 1993 and 1999 in Japan: A chronological and international comparative study. Jpn J Clin Oncol 41: 40-51, 2011.

20. He CZ, Zhang KH, Li Q, Liu XH, Hong Y and Lv NH: Combined use of AFP, CEA, CA125 and CA19-9 improves the sensitivity for the diagnosis of gastric cancer. BMC Gastroenterol 13: 87, 2013

21. Fuchs CS, Tomasek J, Yong CJ, Dumitru F, Passalacqua R, Goswami C, Safran H, dos Santos LV, Aprile G, Ferry DR, et al: Ramucirumab monotherapy for previously treated advanced gastric or gastro-oesophageal junction adenocarcinoma (REGARD): An international, randomised, multicentre, placebo-controlled, phase 3 trial. Lancet 383: 31-39, 2014.

22. Yamada Y, Boku N, Nishina T, Yamaguchi K, Denda T, Tsuji A, Hamamoto Y, Konishi K, Tsuji Y, Amagai K, et al: Impact of excision repair cross-complementing gene 1 (ERCC1) on the outcomes of patients with advanced gastric cancer: Correlative study in Japan Clinical Oncology Group Trial JCOG9912. Ann Oncol 24: 2560-2565, 2013.

23. Tewari M, Kumar A, Mishra RR, Kumar M and Shukla HS: HER 2 expression in gastric and gastroesophageal cancer: Report from a tertiary care hospital in North India. Indian J Surg 77 (Suppl 2): S447-S451, 2015.
24. Ye P, Zhang M, Fan S, Zhang T, Fu H, Su X, Gavine PR, Liu Q and Yin X: Intra-tumoral heterogeneity of HER2, FGFR2, cMET and ATM in gastric cancer: Optimizing personalized healthcare through innovative pathological and statistical analysis. PLoS One 10: e0143207, 2015

25. Zhou Y, Li Y, Zheng J, Liu K and Zhang H: Detecting of gastric cancer by Bcl-2 and Ki67. Int J Clin Exp Pathol 8: 7287-7290, 2015.

26. Philippar U, Roussos ET, Oser M, Yamaguchi $H$, Kim HD, Giampieri S, Wang Y, Goswami S, Wyckoff JB, Lauffenburger DA, et al: A Mena invasion isoform potentiates EGF-induced carcinoma cell invasion and metastasis. Dev Cell 15: 813-828, 2008.

27. Kwiatkowski AV, Gertler FB and Loureiro JJ: Function and regulation of Ena/VASP proteins. Trends Cell Biol 13: 386-392, 2003.

28. Di Modugno F, Bronzi G, Scanlan MJ, Del Bello D, Cascioli S, Venturo I, Botti C, Nicotra MR, Mottolese M, Natali PG, et al: Human Mena protein, a serex-defined antigen overexpressed in breast cancer eliciting both humoral and CD8+ T-cell immune response. Int J Cancer 109: 909-918, 2004.

29. Gertler FB, Niebuhr K, Reinhard M, Wehland J and Soriano P: Mena, a relative of VASP and drosophila enabled, is implicated in the control of microfilament dynamics. Cell 87: 227-239, 1996.

30. Bear JE, Loureiro JJ, Libova I, Fässler R, Wehland J and Gertler FB: Negative regulation of fibroblast motility by Ena/VASP proteins. Cell 101: 717-728, 2000.

31. Drees F and Gertler FB: Ena/VASP: Proteins at the tip of the nervous system. Curr Opin Neurobiol 18: 53-59, 2008.

32. Neel NF, Barzik M, Raman D, Sobolik-Delmaire T, Sai J, Ham AJ, Mernaugh RL, Gertler FB and Richmond A: VASP is a CXCR2-interacting protein that regulates CXCR2-mediated polarization and chemotaxis. J Cell Sci 122: 1882-1894, 2009.

33. Entenberg D, Wyckoff J, Gligorijevic B, Roussos ET, Verkhusha VV, Pollard JW and Condeelis J: Setup and use of a two-laser multiphoton microscope for multichannel intravital fluorescence imaging. Nat Protoc 6: 1500-1520, 2011.

34. Goswami S, Philippar U, Sun D, Patsialou A, Avraham J, Wang W, Di Modugno F, Nistico P, Gertler FB and Condeelis JS: Identification of invasion specific splice variants of the cytoskeletal protein Mena present in mammary tumor cells during invasion in vivo. Clin Exp Metastasis 26: 153-159, 2009.

35. Condeelis J, Singer RH and Segall JE: The great escape: When cancer cells hijack the genes for chemotaxis and motility. Annu Rev Cell Dev Biol 21: 695-718, 2005.

36. Di Modugno F, Mottolese M, Di Benedetto A, Conidi A, Novelli F, Perracchio L, Venturo I, Botti C, Jager E, Santoni A, et al: The cytoskeleton regulatory protein hMena (ENAH) is overexpressed in human benign breast lesions with high risk of transformation and human epidermal growth factor receptor-2-positive/hormonal receptor-negative tumors. Clin Cancer Res 12: 1470-1478, 2006.

37. Gurzu S, Jung I, Prantner I, Ember I, Pávai Z and Mezei T: The expression of cytoskeleton regulatory protein Mena in colorectal lesions. Rom J Morphol Embryol 49: 345-349, 2008.

38. Di Modugno F, DeMonte L, Balsamo M, Bronzi G, Nicotra MR, Alessio M, Jager E, Condeelis JS, Santoni A, Natali PG and Nisticò P: Molecular cloning of hMena (ENAH) and its splice variant hMena+11a: Epidermal growth factor increases their expression and stimulates hMena+11a phosphorylation in breast cancer cell lines. Cancer Res 67: 2657-2665, 2007. 